\title{
GEOCHEMISTRY OF ATMOSPHERIC DUST ON THE TERRITORY OF THE CITY OF YEREVAN
}

\author{
Armen Saghatelyan ${ }^{a}$, Lilit Sahakyan ${ }^{a *}$, Olga Belyaeva ${ }^{a}$ \\ ${ }^{a}$ The Center for Ecological-Noosphere Studies NAS RA, 68 Abovian Str., 0025 Yerevan, Republic of Armenia \\ phone: (+374 10)572924, fax: (+374 10)572938, e-mail: ecocentr@sci.am,http://www.ecocentre.am,*svlilit@yahoo.com
}

\begin{abstract}
This research is focused on the level of heavy metal contents in dust of a near-ground layer of atmosphere. The dust load level was evaluated as medial. Indicated was a quality composition of dominating dust pollutants. The level of summary load of metals was low.
\end{abstract}

Keywords: urban air pollution, dust load, heavy metals

\section{Introduction}

The air basin is a transit environment for diverse pollutants and particularly heavy metals in which they travel and disperse. Heavy dust load in cities in combination with high concentrations of heavy metals in the dust is a risk factor to public health.

The goal of this research was evaluation of both dust load on the territory of the city of Yerevan and the contents of harmful components - heavy metals - in the dust with help of snow survey data. The research was performed in 2011.

Yerevan is the capital city of Armenia. It covers an area of $227 \mathrm{sq} . \mathrm{km}$, its population is 1117800 people which makes over $24 \%$ of the population of the republic. Yerevan is not only the administrative and economic center but also an essential transport junction of the country. The geological composition of the territory is dominated by volcanic lavas, tuffs and Quaternary sediments characterized by close-to-clarke contents of heavy metals. The rocks display development of brown and semi-desert soils. The soil profile is rich in carbonates, to the lower horizon the presence of gypsum is common, this evidencing a lack of chemical element washout and creating a good environment for heavy metal accumulation on soil profiles. The natural geochemical association is characterized by a weakly intensive series represented by $\mathrm{Zn}, \mathrm{Cu}$ and $\mathrm{Co}$. So, the pronounced geochemical anomalies of heavy metals in diverse environmental compartments emphasizing the atmospheric dust of Yerevan are of man-made origin.

\section{Materials and methods}

One of best informative indicators of dust pollution of the air basin in winter period is snow cover. Due to its good sorption property snow absorbs the major part of dust from the ambient air. The investigations were implemented in compliance with methods described in detail [1,2].

Snow was sampled from a fixed site. Then the snow samples were transported to the lab and filtered and dried after melting. A dry residue was analyzed for concentrations of eleven elements ( $\mathrm{Hg}, \mathrm{Cd}, \mathrm{As}, \mathrm{Pb}, \mathrm{Cr}, \mathrm{Ni}, \mathrm{Co}, \mathrm{Zn}, \mathrm{Cu}, \mathrm{Ag}$ and Mo) on a PerkinElmer AAS AAnalist 800. Total 18 snow samples were collected and analyzed.

The dust load $(P)$ was calculated by a formula $P=P_{0} / S \cdot t$, where $P_{0}$ is the mass of filtered substance, $S-$ a sampling site area, $t-$ a fell snow layer formation time (in the considered case -1 day) [1, 2]. The dust load level was assessed with help of a 4-grade scale suggested by N.S. Kasimov [3].

With a goal to identify heavy metal anomalies in dust, collation was done between the contents of heavy metals and a geochemical background for soils $[7,6]$. To characterize quality and quantity indices of heavy metal anomalies in dust, arranged were ranked geochemical series of heavy metal contents in soils graded by concentration coefficients: $K_{c}=C_{i} / C_{\text {background }} K_{c}=C_{i} / C_{\dot{\varphi} o u}$, where $C_{i}$ is the contents of $i$ metal in dust, $\mathrm{C}_{\text {background }}-$ its background contents in soils.

\section{Results and Discussion}

According to snow cover survey data for Yerevan for 2011, the major part of the territory displayed low levels of dust load (less than $250 \mathrm{~kg} / \mathrm{sq} . \mathrm{km} /$ day). However, against the background of a low dust level $28 \%$ of the studied samples displayed a high dust load (varying 450-800 kg.sq.km/day), those values corresponding to a high level of danger. And finally $11 \%$ of samples displayed a very high dust level (over $800 \mathrm{~kg} . \mathrm{sq} . /$ day), which corresponds to an extremely high level of danger [3]. 
Thus, Yerevan's air basin is characterized by a presence of sharp peaks against a background of low dust load values (Fig.1).

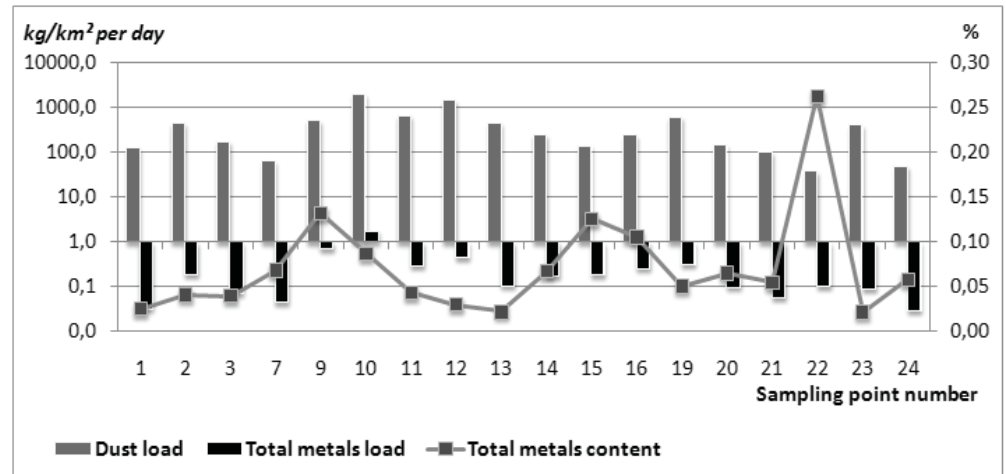

Fig.1. Dust load, summary load of heavy metals and summary contents of heavy metals in the dust of Yerevan.

A summary mass share of heavy metals in atmospheric dust varies within 2 orders: from $0,02-0,26 \%$ and averages to $0,07 \%$. A summary load of heavy metals varies 0,03 to $1,81 \mathrm{~kg} / \mathrm{sq} \cdot \mathrm{km} /$ day and the value of this index for the city averages $0,28 \mathrm{~kg} / \mathrm{sq} . \mathrm{km} /$ day. Commonly, the value of summary load of heavy metals is directly proportional to the value of dust load (Fig.1). It is noteworthy that on the average $99 \%$ of total sum of heavy metals in dust is made by six elements only, which include elements of $1^{\text {st }}$ grade of danger $-\mathrm{Pb}$ and $\mathrm{Zn}$ and $2^{\text {nd }}$ grade of danger $-\mathrm{Cu}, \mathrm{Mo}, \mathrm{Ni}$ and $\mathrm{Cr}$. $1 \%$ of the sum of metal falls on Co, Ag and three toxic elements: $\mathrm{Hg}$, Cd and As (Fig.2).

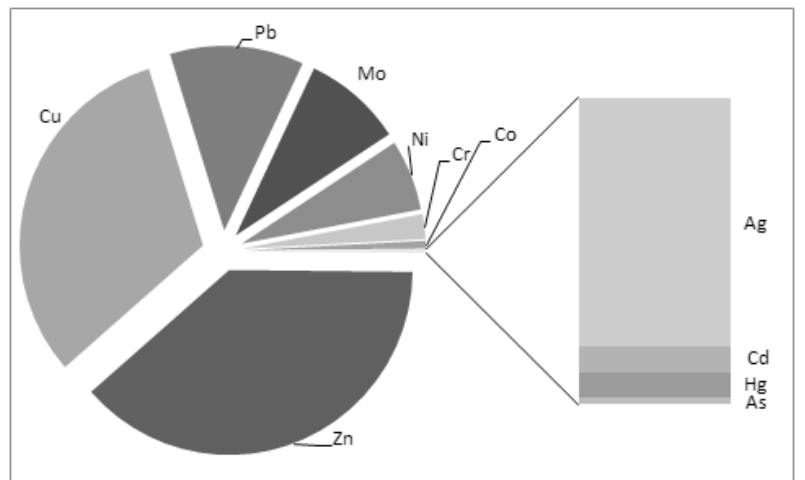

Fig.2. Averaged shares of heavy metals in the dust of the snow cover in Yerevan.

Heavy metal concentrations in dust are given in Tab.1, their collation with the geochemical background of Yerevan's soils - in Fig.3.

Table 1

Heavy metal contents and their geochemical series in atmospheric dust of Yerevan.

\begin{tabular}{|c|c|c|c|c|c|c|c|c|c|c|c|}
\hline \multirow{2}{*}{ Index } & \multicolumn{5}{|c|}{ I grade of danger } & \multicolumn{5}{|c|}{ II grade of danger } & \multirow{2}{*}{$\frac{-}{\mathrm{Ag}}$} \\
\hline & $\mathrm{Hg}$ & Cd & As & $\mathbf{P b}$ & $\mathbf{Z n}$ & $\mathrm{Cr}$ & $\mathbf{N i}$ & Co & $\mathrm{Cu}$ & Mo & \\
\hline background & - & - & 10 & 40 & 100 & 68 & 35 & 10 & 60,00 & 12 & 0,05 \\
\hline$C_{\text {min }}$, & 0,01 & 0,02 & 0,001 & 11,35 & 64,16 & 2,52 & 11,06 & 0,27 & 24,47 & 8,86 & 0,29 \\
\hline$K_{c}$ & - & - & 0,0001 & 0,28 & 0,64 & 0,04 & 0,32 & 0,03 & 0,41 & 0,74 & 5,78 \\
\hline \multicolumn{12}{|c|}{$\mathrm{Ag}_{(5,8)}$} \\
\hline$C_{\max }, \mathrm{mg} / \mathrm{kg}$ & 1,18 & 0,54 & 0,04 & 876,5 & 749,0 & 38,13 & 66,07 & 6,02 & 1853,5 & 216,9 & 4,13 \\
\hline$K_{c}$ & - & - & 0,004 & 21,91 & 7,49 & 0,56 & 1,89 & 0,60 & 30,89 & 18,08 & 82,54 \\
\hline \multicolumn{12}{|c|}{$\mathrm{Ag}_{(82,5)}-\mathrm{Cu}_{(30,9)}-\mathrm{Pb}_{(21,1)}-\mathrm{Mo}_{(18,1)}>\mathrm{Zn}_{(7,5)}-\mathrm{Ni}_{(1,9)}$} \\
\hline$C_{\mathrm{avr}}, \mathrm{mg} / \mathrm{kg}$ & 0,20 & 0,12 & 0,02 & 94,62 & 243,89 & 13,45 & 34,29 & 3,50 & 275,01 & 57,30 & 1,50 \\
\hline$K_{c}$ & - & - & 0,002 & 2,37 & 2,44 & 0,20 & 0,98 & 0,35 & 4,58 & 4,78 & 30,09 \\
\hline \multicolumn{12}{|c|}{$\mathrm{Ag}_{(30,1)}>\mathrm{Mo}_{(4,8)}-\mathrm{Cu}_{(4,6)}-\mathrm{Zn}, \mathrm{Pb}_{(2,4)}-\mathrm{Ni}_{(1,0)}$} \\
\hline
\end{tabular}

Note: "-" - no data are available 
As seen from data given in Tab.1 and Fig.3, maximal excesses vs. geochemical series are established for Ag which is a dominating dust pollutant in Yerevan. $\mathrm{K}_{\mathrm{c}}$ values for $\mathrm{Ag}$ show a one order excess as compared with those for an analogous index for other elements

The values of coefficients of concentrations of the elements of $2^{\text {nd }}$ grade of danger Mo and $\mathrm{Cu}$ are similar; the noted elements are always found in the dust of the near-ground atmospheric layer of Yerevan. Moreover, the dust displays a stable presence of $\mathrm{Ni}$ in close-to-background concentrations.

$K_{c}$ values of the elements of $1^{\text {st }}$ grade of danger are also similar. Only one sample displayed a single high concentration of $\mathrm{Pb}$, but wholly $K_{c}$ of this element is rather low. Arsenic (As) was indicated in 4 dust samples in concentrations which were well low vs. the geochemical background. Toxic elements $\mathrm{Hg}$ and $\mathrm{Cd}$ were indicated in all the collected samples in rather low concentrations. For $\mathrm{Hg}$ and $\mathrm{Cd}$ no geochemical background values have been calculated.

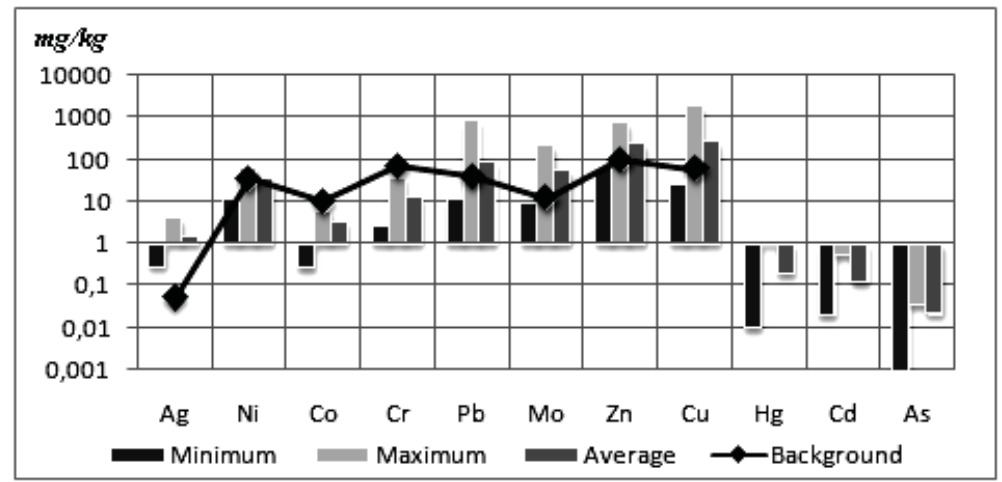

Fig. 3. Heavy metal concentrations in dust vs. the geochemical background for soils on Yerevan's territory

Qualitative and quantitative characteristics of atmospheric dust are clearly expressed in a geochemical series ranked by coefficients of concentrations. The averaged geochemical series is arranged as follows: $\mathrm{Ag}_{(30,1)}>\mathrm{Mo}_{(4,8)}-\mathrm{Cu}_{(4,6)}-\mathrm{Pb}, \mathrm{Zn}_{(2,4)}-\mathrm{Ni}_{(1,0)}$. The summary intensity of the averaged geochemical series of heavy metals in dust makes 45,3, which corresponds to the acceptable level of dust pollution with heavy metals [3].

Investigations of geochemical indices of dust migration flow on Yerevan's territory have a character of monitoring. Drastic quality and quantity changes in geochemical anomalies has been recorded since 2002. In period 1989-2001 geochemical series were dominated by $\mathrm{Pb}[7]$.

However, in 2001 the use of ethylated gasoline was banned, so $\mathrm{Pb}$ emissions into the atmosphere got reduced. In $2002 \mathrm{~Pb}$ was shifted from leading positions in geochemical series, and dominating dust pollutants has become Ag, $\mathrm{Mo}, \mathrm{Cu}$ and $\mathrm{Zn}$.

Besides, since 2002 the intensity of geochemical anomalies in the dust of Yerevan has been declining. Also, since 2002 the summary share of heavy metals in dust has reduced. Despite the fact, that between 2002 and 2011 a dust load level on the major part of the city showed insignificant variations, noteworthy is a sharp reduction of the share of heavy metal in dust and consequently the intensity of geochemical anomalies in dust depositions decreased by 2,6 times: from 122 in 2001 to 45,3 in 2011. So, the intensity of the averaged geochemical series in 2011 was by 2,6 times lower as compared with a similar index for 2002.

With a goal of providing a sanitary and hygienic assessment, concentrations of heavy metals in dust were collated with MAC for soils established for Armenia [1]. MAC exceeding values were indicated for five elements (Fig.4), including those of $1^{\text {st }}(\mathrm{Pb}, \mathrm{Zn})$ and $2^{\text {nd }}(\mathrm{Cu}, \mathrm{Co}, \mathrm{Mo})$ grades of danger.

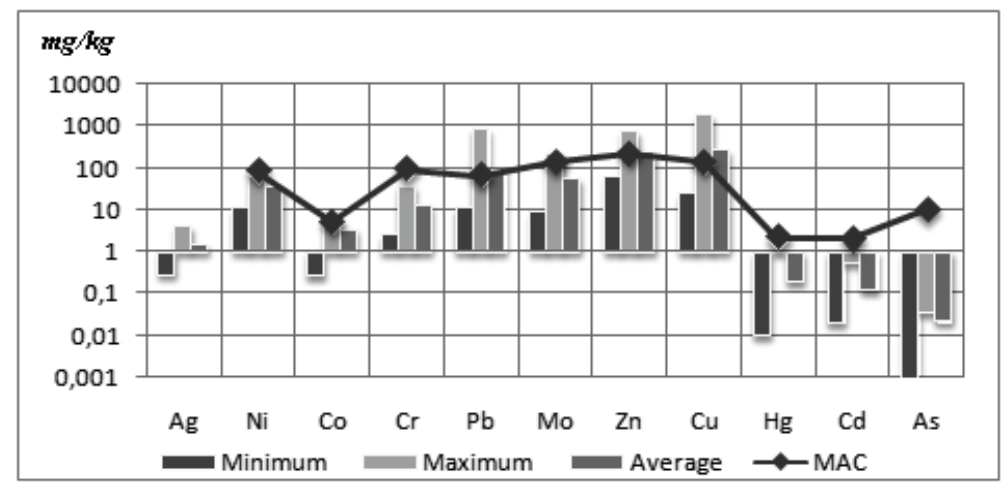

Fig. 4. Excessive heavy metal concentrations in dust vs. MAC for soils [1]. 


\section{Conclusion}

The performed investigations support the following conclusion. The major part of Yerevan displays low values of dust load: against such a background sharp peaks are recorded which corresponds to high and extremely high level of danger. The summary shares of heavy metals in dust vary 0,02 to $0,26 \%$ and average to $0,07 \%$. The intensity of geochemical series of heavy metal anomalies is low, and against this background single peaks are detectable. $99 \%$ of summary share of heavy metals falls on six elements, including those of the $1^{\text {st }}(\mathrm{Pb}, \mathrm{Zn})$ and $2^{\text {nd }}(\mathrm{Cr}, \mathrm{Cu}, \mathrm{Mo}, \mathrm{Ni})$ grades of danger. Dominating atmospheric dust pollutants on the territory of Yerevan were Ag, Mo and $\mathrm{Cu}$. In a period 2002 to 2011 quality and quantity indices of geochemical anomalies of heavy metals in dust showed a steady inclination to reduction.

\section{References}

[1]. Methodic requirements on geochemical assessment of environmental pollution sources. Saet YU.E., Barashevich, I.L.; Revich, B.A. M. Publ.h. IMGRE 1982, 66 pp. (in Russian)

[2]. Methodic requirements on geochemical assessment of pollution of urban territories with chemical elements. Revich B.A et al.: M. Publ.h. IMGRE 1982, 112 pp. (in Russian)

[3]. Perelman, A.I.; Kasimov, N.S. Landscape geochemistry. M.: Astrea-2000, 1999, 768pp. (in Russian)

[4]. RA Government Resolution № 92-Nas of 25January 2005 "About approval of the order of assessment of the economic activities - induced impact on soil resources. Yerevan, 2005. Electronic resource, http://www.arlis.am/\#, open access (in Armenian).

[5]. Resolution № 01-N as of 25 January 2010. About approval of of sanitary guidelines and norms №2.1.7.003-10 "Soils quality hygienic requirements" RA Ministry of Health Electronic resource, http://www.arlis.am/\#, open access (in Armenian)

[6]. Saghatelyan, A.K. The Peculiarities of heavy metal distribution on Armenia's territory. Monograph. Yerevan: Publ.h. Center for Ecological-Noosphere Studies NAS RA, 2004, 157 pp. (in Russian)

[7]. Sahakyan, L.V. (2006) The Assessment of Heavy Metal Stream in the Air Basin of Yerevan / 7th International Symposium on Environmental Geochemistry, 24-30 September, 2006, Beijing, China, pp. 95-96. 